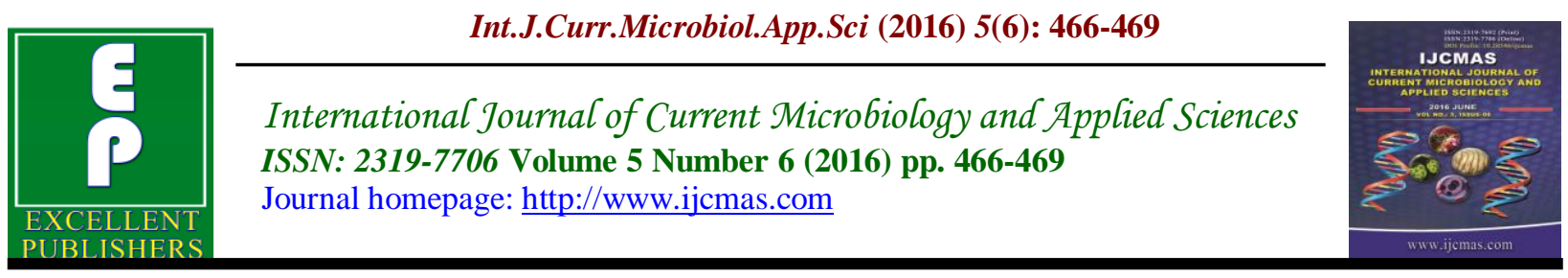

Original Research Article

http://dx.doi.org/10.20546/ijcmas.2016.506.053

\title{
Seroprevelance of Hepatitis B Surface Antigen in Hospital based Population in Southern Rajasthan, India
}

\author{
Deepika Atray*, Anshu Sharma and Meena Atray \\ Department of Microbiology, R.N.T. Medical College and Hospital \\ Udaipur (Rajasthan), India \\ *Corresponding author
}

\begin{abstract}
A B S T R A C T
Keywords

HBsAg,

Seroprevelance, immunoassay,

Southern

Rajasthan.

Article Info

Accepted:

20 May 2016

Available Online:

10 June 2016

Hepatitis B is a fatal disease widespread around the country. HBsAg is the most common marker of infection for diagnosis and screening. An individual positive for $\mathrm{HBsAg}$ is considered to be infected with $\mathrm{HBV}$, and is therefore potentially infectious. In the present study, we observed the seroprevelance of HbsAg among population of at a tertiary care teaching hospital in southern Rajasthan from March 2016 to May 2016.The test was conducted using one step rapid card immunoassay. We observed $0.75 \%$ positivity in samples of $\mathrm{HbsAg}$ out of which female prevalence was more as compared to males that was $11.2 \%$ and $8.8 \%$ respectively. Highest Prevalence was seen among age group of 20-40 years population. Our study highlights about the seropositivity of HBsAg among population of southern Rajasthan and also shows its relation with age and sex of the population.
\end{abstract}

\section{Introduction}

Hepatitis B virus is a partially doublestranded circular DNA virus and is a member of the Hepadnaviridae family. The virus consists of a core capsid which contains viral DNA and this is surrounded by an envelope containing surface antigen (HBsAg). The HBsAg particles vary greatly in morphology and are found in high concentrations in early acute infection and continue to be produced in chronic disease. HBsAg is the most commonly used marker of infection for diagnostic and blood screening. An individual positive for $\mathrm{HBsAg}$ is considered to be infected with $\mathrm{HBV}$, and is therefore potentially infectious (World Health Organization, 2004).
Of the approximately 2 billion people, who have been infected worldwide more than 350 million are chronic carriers of HBV. (Behel et al., 2008)

At least $15-25 \%$ of chronically HBV infected people die due to liver disease caused by HBV and this constitutes nearly one million people each year. It is the most common cause of chronic liver disease, including cirrhosis of the liver and hepatocellular carcinoma worldwide. An effective vaccine is available for over two decades and has brought about remarkable changes in the global epidemiology of HBV infection (Chowdhary et al., 2004). 
A hepatitis B vaccine, available since 1982, has a high efficacy in the prevention of HBV transmission and has brought about remarkable changes in the global epidemiology of HBV infection (Baha et al., 2013).

To understand and assess the magnitude and dynamics of transmission of a disease in a community and for its control and prevention, the assessment and study of its prevalence is very important. Communitybased seroprevalence studies are difficult to conduct in a developing country because of socioeconomic hurdles and logistic difficulties (Sood et al., 2010).

The present study was designed to study the seroprevelance of HBsAg using one step rapid card immunoassay among inpatients and outpatients at a tertiary care teaching hospital in southern Rajasthan.

The main objectives of this study includes, to Evaluate the seroprevelance of HBsAg among population of Southern Rajasthan using immunochromatographic rapid card test from March 2016 to May 2016.

\section{Materials and Methods}

2000 samples of both indoor and outdoor patients were evaluated from the duration of March 2016 to May 2016.

Two $\mathrm{ml}$ venous blood of patients was collected and kept at room temperature to clot. The serum was separated by low centrifugation to get a clear supernatant.

The serum was subjected to Hepaview immunochromatographic card test which is a one step rapid quantitative two site sandwich immunoassay. As the test sample flows through the membrane assembly of the device, the colored monoclonal anti HBsAg colloid gold conjugate complexes with HBsAg in the sample. This complex moves further to the test region where it is immobilized by another monoclonal anti HBsAg antiserum coated on the membrane leading to the formation of pink purple colored band which confirms positive result.

Only one pink band at the control region gives a negative test

Two pink bands both at the control and the test region gives a positive test.

The positive results were reconfirmed using a second card test.

\section{Results and Discussion}

In the present study, total of 2000 samples were tested for HBsAg .Out of 2000 samples tested 15 samples were found to be positive. So the seroprevalance of HBsAg is found to be $0.75 \%$ of the total population examined in duration of 3 months.

Out of total samples tested $44 \%(880 / 2000)$ were males while $56 \%$ (1120/2000) were females. Positive males were $8.8 \%$ (5/880) while positive females were $11.2 \%$ $(10 / 1120)$ as shown in table1.

Highest positivity was found to be in $53.3 \%$ $(8 / 15)$ in age group of $20-40$ years .In this female prevalence was high i.e.75\% (6/8) as compared to males i.e.25\% (2/8).Positivity in age group 40-60 was found to be $20 \%(3 / 15)$ and lesser in age groups 0-20 and above 60 years i.e. $13.33 \%(2 / 15)$ as shown in table 2 .

The carrier rate of Hepatitis B in India is different in the different regions of the country. The overall carrier rate is often quoted as being $4.7 \%$. This is the weighted mean of various studies and includes high risk populations (Bathem et al., 2007). 
Present study depicts a $0.75 \%$ prevelance of HBsAg in the population of southern Rajasthan. Similar studies conducted show variable results in reference to seroprevalance of $\mathrm{HBsAg}$ contrasting our study. Kanodia et al., (2015) noted 4.7\% seropositive cases of HBsAg in the hospital based population at Jaipur.

Choudhary et al., (2007) gave $2.28 \%$ seropositiviity at surgical out patients department of Fauji Foundation Hospital, Rawalpindi. Similarly Patil et al., (2011) noted a prevalence of $2.99 \%$ in Solapur district of Maharashtra, India.

But similar results to our study were shown by Sood et al., who observed $0.87 \%$ of prevelance of HBsAg in hospital based population. Results of our study are very near to study by Sood et al.

\section{Sex Based Prevalence}

In our study, out of total samples studied $44 \%$ were males while $56 \%$ were females. Out of these higher positivity was observed in females as compares to males which was seen to be $8.8 \%$ and $11.2 \%$ respectively.
Similar results were shown by study conducted by Vohra et al., (2015) in Haryana where female prevalence was $.77 \%$ which was more as compared to males which was $49 \%$.

While some of the studies show some contradiction to our study and show higher male prevelance as compared to females.

Kanodia et al., (2015) observed higher male prevalence i.e. $3.07 \%$ as compared to $1.06 \%$ female prevelance.

Patil et al., (2011) also observed 1.87\% male prevalence which was higher as compared to $1.17 \%$ female prevalence.

\section{Age Based Prevalence}

In our study the age group of 21-40 years was found to have highest prevalence rate with seropositivity of $53.3 \%$ of total positive population. Out of these, $75 \%$ were females while $25 \%$ were males. Least positive (13.33\%) were found to be in children and adolescent of age group 0-20 and in older age group of 60 and above. The male and female ratio was equal in both the age groups $(6 \%)$.

Table.1 Shows sex wise distribution of HBsAg positive samples

\begin{tabular}{|l|l|l|}
\hline & Male & Female \\
\hline Total Tested & $880(44 \%)$ & $1120(56 \%)$ \\
\hline Positive & $5(8.8 \%)$ & $10(11.2 \%)$ \\
\hline
\end{tabular}

Table.2 Shows age wise distribution of the positive HBsAg samples.

\begin{tabular}{|l|l|l|l|l|}
\hline Age Distribution & $\begin{array}{l}\text { No.of } \\
\text { positive(15) }\end{array}$ & \% positive & Males positive & Females positive \\
\hline $0-20$ & 2 & $13.3 \%$ & $1(6 \%)$ & $1(6 \%)$ \\
\hline $21-40$ & 8 & $53.3 \%$ & $2(25 \%)$ & $6(75 \%)$ \\
\hline $41-60$ & 3 & $20 \%$ & $1(33.3 \%)$ & $2(66.6 \%)$ \\
\hline 61 and above & 2 & $13.3 \%$ & $1(6 \%)$ & $1(6 \%)$ \\
\hline
\end{tabular}


Similar results were found by Kanodia et al., (2015) with maximum prevalence in age group 21-40 i.e $40.39 \%$. Minimum prevalence was seen in age group 0-20 yrs and 60 yrs above. However male prevalence was more as compared to female prevalence which contradicts our study.

Behel et al., (2008) observed maximum positivity in age group 35-45 which is $3.03 \%$.and minimum in age groups 19-25 and 45-55yrs. However they also observed more male prevalence as compared to female.

These observation depict the prevalence of HBsAg is high in the age group of 20-40 years. The reason may be lack of proper knowledge and maximum exposure to the possible causes of the disease.

In conclusion, our study emphasizes on the present prevalence of $\mathrm{HBsAg}$ among the population of southern Rajasthan. In the present scenario, a large amount of population infected with the disease in acute or chronic stage and is potent in transmission of the disease. Various measures to create awareness among general population should be taken along with the vaccination.

\section{References}

Baha, et al., 2013. Prevalence and risk factors of hepatitis $\mathrm{B}$ and $\mathrm{C}$ virus infections among the general population and blood donors in
Morocco. DOI: 10.1186/1471-2458-13-50.

Behal, et al., 2008. Seroprevalence and risk factors for hepatitis B virus infection among general population in Northern India, Arq. Gastroenterol., 45(2).

Bathem, et al., 2007. Systematic Review and Meta-analysis of Prevalence of Hepatitis B in India. Indian Paediatrics, 44: 663-674.

Choudhary, et al., 2007. Seroprevalence of hepatitis-B and $\mathrm{C}$ among the patients reporting in surgical OPD at Fauji Foundation Hospital, Rawalpindi: Review of 5 year literature. Pak. J. Med. Sci., 23(4): 514-517.

Chowdhury, A. 2004. Epidemiology of hepatitis $\mathrm{B}$ virus infection in India. Hep. B. Annual., 1: 17-24.

Kanodia, et al. 2015. Seroprevalence of Hepatitis B surface antigen in hospital based population of Jaipur, Rajasthan. MedPulse - Int. Med. J., 2(3): 123-125.

Patil, et al. 2011. Prevalence of hepatitis-B surface antigen (HBsAg) positivity in Solapur District, Maharashtra State, India. Bangladesh J. Med. Sci., 10(2): 91-94.

Sood, S., Malvankar, S. 2010. Seroprevalence of Hepatitis B surface antigen, antibodies to the Hepatitis $\mathrm{C}$ virus, and human immunodeficiency virus in a hospital-based population in Jaipur, Rajasthan. Indian J. Community Med., 35: 165-9.

Vohra, et al. 2015. Seroprevalence of Blood Borne Viral Infections in a Tertiary Care Centre in Remote Settings of Mewat, Haryana, India. Int. J. Curr. Microbiol. App. Sci., 4(3): 222-227.

World Health Organization. 2004. Hepatitis B surface antigen assays: operational characteristics (phase1) report 2: 2-10.

\section{How to cite this article:}

Deepika Atray, Anshu Sharma and Meena Atray. 2016. Seroprevelance of Hepatitis B Surface Antigen in Hospital based Population in Southern Rajasthan, India. Int.J.Curr.Microbiol.App.Sci. 5(6): 466-469. doi: http://dx.doi.org/10.20546/ijcmas.2016.506.053 